\title{
Analiza morfologii przełomów udarnościowych złączy spawanych ze staliwa dla energetyki typu Cr-Mo $z$ dodatkiem metali ziem rzadkich
}

\author{
Analysis of the morphology of impact fractures \\ of welded joints made of cast steel for the power industry \\ of the Cr-Mo type with the addition of rare earth metals
}

\section{Streszczenie}

W artykule przedstawiono wyniki badań makro- i mikroskopowych oraz pomiary twardości doczołowych złączy spawanych ze staliwa G17CrMo5-5. Ponadto została przeprowadzona analiza morfologii przełomów udarnościowych złączy spawanych. Złącza spawane wykonano metodą TIG.

Słowa kluczowe: staliwo; spawanie; TIG; twardość; morfologia

\section{Abstract}

The article presents the results of tests of butt welded joints, ie. hardness distribution, macro and microstructure. Analysis of surface morphology of impact fractures of G17CrMo5-5 welded joints was carried out. The welding process was carried out on two types of melts, ie. without modification and with addition of rare earth metals (REM) to liquid metal. Welded joints were made using the TIG method.

Keywords: cast steel; welding; TIG; hardness; morphology

\section{Wstęp}

Przełomy dostarczają szereg informacji dotyczących mechanizmu pękania, a szczegółowa analiza fraktograficzna - o czynnikach wewnętrznych i zewnętrznych jakie miały wpływ na proces niszczenia. Obserwacje makroskopowe złomów awaryjnych pozwalają na wstępne określenie przyczyny uszkodzenia materiału podczas eksploatacji zależnej od warunków pracy oraz środowiska. Obserwacje mikroskopowe natomiast umożliwiają wykrycie wad materiałowych takich jak występowanie skupisk wydzieleń oraz faz międzymetalicznych lub rodzaj i gęstość dyslokacji w substrukturze $[1,2]$. Analiza przełomów udarnościowych jest również istotna w przypadku stali konstrukcyjnych, które charakteryzują się znaczną wytrzymałością przy niskich własnościach plastycznych [3]. W przypadku stopów odlewniczych szczególnie ważne jest określenie wpływu czynników strukturalnych na proces inicjacji i propagacji pęknięć. Szereg stopów odlewniczych modyfikuje się mikrododatkami lub poprzez optymalizację procesu technologicznego. Wprowadzenie powyższych czynników ma wpływ na charakter oraz udział przełomów łupliwego do ciągliwego [4]. Istotna jest również temperatura, w których przeprowadza się testy [5].

\section{Materiał do badań}

Złącza spawane wykonano ze staliwa G17CrMo5-5 (tabl. I). Wytopy staliwa prowadzono w warunkach przemysłowych w piecu indukcyjnym o pojemności $2000 \mathrm{~kg}$. Przeprowadzono dwa rodzaje wytopów tj. bez modyfikacji oraz z wprowadzeniem metali ziem rzadkich (MZR) do ciekłego metalu. Metale ziem rzadkich wprowadzono w postaci miszmetalu o składzie chemicznym: 49,8\% Ce; 21,8\% La; $17,1 \%$ Nd; 5,5\% Pr oraz 5,35\% reszty MZR.

Tablica I. Skład chemiczny staliwa G17CrMo5-5 wg PN-EN-10213-2, \%

Table I. Chemical composition of G17CrMo5-5 cast steel according to PN-EN-10213-2,\%

\begin{tabular}{|c|c|c|c|c|c|c|c|c|}
\hline $\mathbf{C}$ & Si & Mn & Cr & Mo & Ni & Al & S & P \\
\hline 0,18 & 0,4 & 0,9 & 1,2 & 0,53 & 0,07 & 0,041 & 0,015 & 0,022 \\
\hline
\end{tabular}

Dr inż. Andrzej Skrzypczyk, dr inż. Justyna Kasińska, mgr inż. Piotr Furmańczyk - Politechnika Świętokrzyska w Kielcach. Autor korespondencyjny/Corresponding author: pfurmanczyk@tu.kielce.pl 
Próbki zostały pobrane z wlewków próbnych, które poddano obróbce cieplnej polegającej na wyżarzaniu normalizujące$\mathrm{mu}\left(940^{\circ} \mathrm{C} / 1 \mathrm{~h} / \mathrm{pow}\right.$.) oraz odpuszczaniu $\left(710^{\circ} \mathrm{C} / 2 \mathrm{~h} / \mathrm{pow}\right.$.). W wyniku tak przeprowadzonej obróbki cieplnej uzyskano mikrostrukturę staliwa przedstawioną na rysunku 1 [6]. Wprowadzenie mischmetalu do staliwa przyniosło znaczący wzrost udarności staliwa zachowując przy tym własności plastyczne na niezmienionym poziomie (tabl. II) [7]. Zakładając korzystne oddziaływanie modyfikacji na materiał w warunkach obniżonych temperatur eksploatacyjnych staliwo poddano badaniom wytrzymałościowym w obniżonych temperaturach. Badania przeprowadzono zgodnie z normą ASTM E 1737-96 [8] na próbkach trójpunktowo zginanych w zakresie temperatur od $+20{ }^{\circ} \mathrm{C}$ do $-60^{\circ} \mathrm{C}$ dla staliwa niemodyfikowanego oraz do $-80{ }^{\circ} \mathrm{C}$ dla staliwa z metalami ziem rzadkich. Wyznaczono wartości odporności na pękanie $\mathrm{K}_{\mathrm{Jc}}$ (rys. 2) oraz temperaturę przejścia w stan kruchy $T_{a}$, która dla staliwa modyfikowanego wyniosła $-51,2^{\circ} \mathrm{C}$, a dla niemodyfikowanego $1,1^{\circ} \mathrm{C}[7,9]$.

Tablica II. Własności mechaniczne staliwa G17CrMo5-5 Table II. Mechanical properties of G17CrMo5-5 cast steel

\begin{tabular}{|c|c|c|c|c|c|}
\hline G17CrMo5-5 & $\begin{array}{c}\mathbf{R}_{\mathbf{e}}, \\
\mathbf{M P a}\end{array}$ & $\begin{array}{c}\mathbf{R}_{\mathbf{m}}, \\
\mathbf{M P a}\end{array}$ & $\begin{array}{c}\mathbf{A}_{\mathbf{5}}, \\
\%\end{array}$ & $\begin{array}{c}\mathbf{Z}, \\
\%\end{array}$ & $\begin{array}{c}\mathbf{K V}, \\
\mathbf{J} / \mathbf{c m}^{2}\end{array}$ \\
\hline $\begin{array}{c}\text { Bez dodatku } \\
\text { MZR }\end{array}$ & 507,4 & 661 & 20,08 & 63,6 & 30 \\
\hline $\begin{array}{c}\text { Z dodatkiem } \\
\text { MZR }\end{array}$ & 551,4 & 685,2 & 19,92 & 62,4 & 99 \\
\hline
\end{tabular}
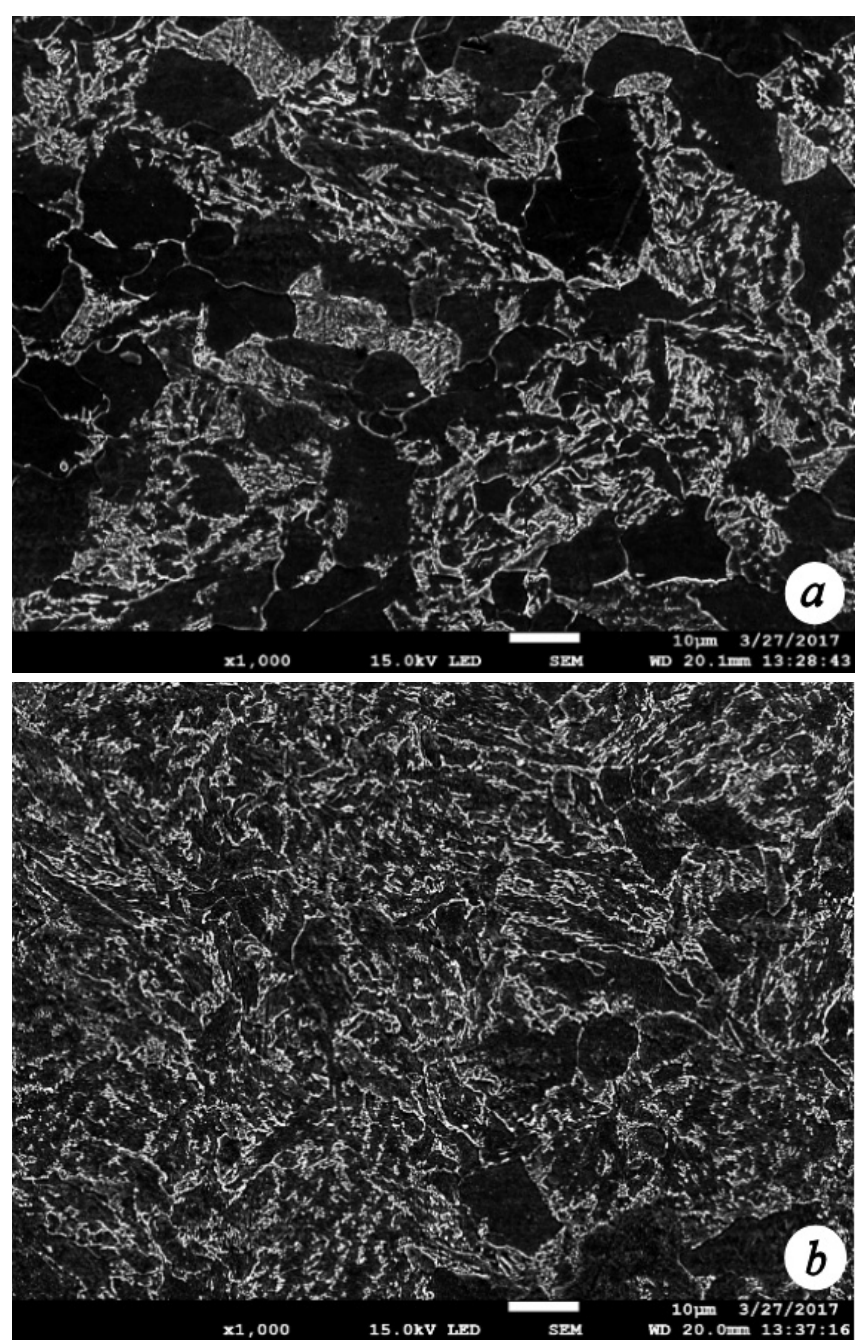

Rys. 1. Mikrostruktura staliwa G17CrM05-5: a) staliwo niemodyfikowane, b) staliwo z dodatkiem MZR

Fig. 1. Microstructure of G17CrM05-5 cast steel: a) unmodified cast steel, b) cast steel with the addition of MZR

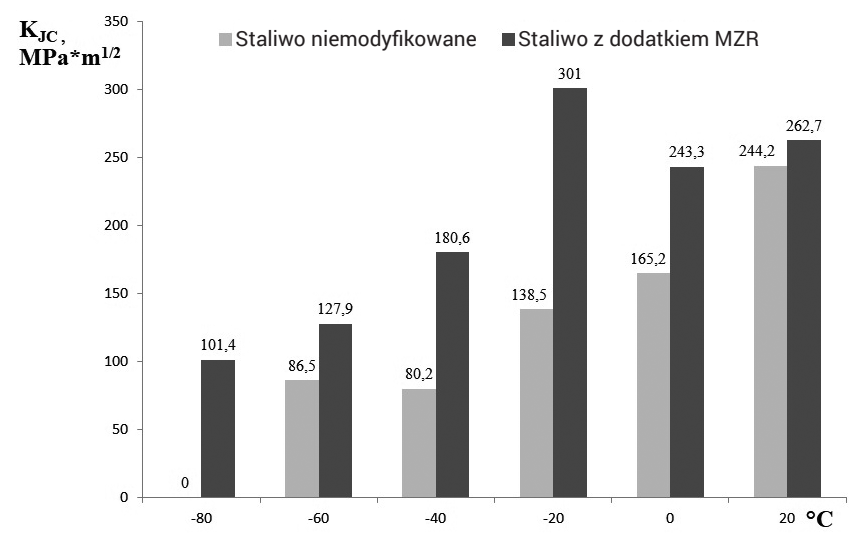

Rys. 2. Wykres odporności na pękanie staliwa G17CrMo5-5

Fig. 2. Diagram of resistance to cracking of the G17CrMo5-5 cast steel

\section{Wykonanie złączy próbnych}

Z wlewków próbnych ze staliwa G17CrMo5-5 pobrano próbki, z których wykonano złącza doczołowe o grubości $12 \mathrm{~mm}$ spawane metodą TIG. Sposób przygotowania brzegów próbek do spawania oraz warunki technologiczne spawania podano w pracy [10]. Spawanie realizowano w osłonie argonu - 11 [11] z zastosowaniem spoiwa LNT/LNM-19 [12]. Zabiegi cieplne towarzyszące spawaniu podano na rysunku 3.

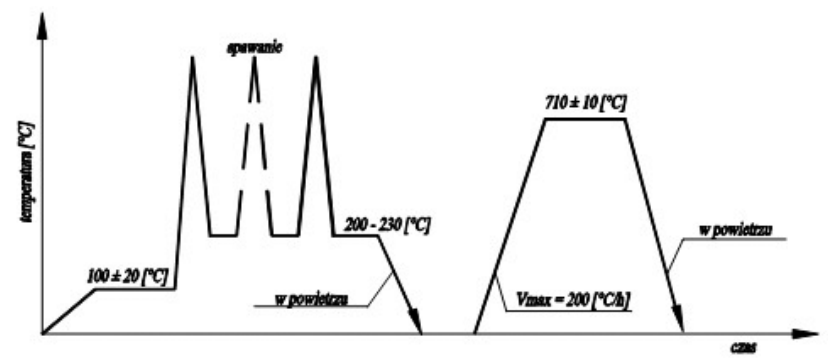

Rys. 3. Wykres zabiegów cieplnych w czasie spawania staliwa G17CrMo5-5

Fig. 3. Graph of heat treatments during welding of G17CrMo5-5 cast steel

\section{Wyniki badań}

Przedstawione na rysunku 4 [6] złącza spawane wykonane metodą TIG charakteryzują się poprawną budową. Dla złączy z obu wytopów uzyskano zbliżone rozkłady twardości na przekrojach poprzecznych. Twardość poszczególnych odcinków złącza spawanego w stanie wyjściowym oraz po wyżarzaniu odprężającym nie przekraczała $280 \mathrm{HV}$.

\section{Badania makrostruktury doczołowych złączy spawanych}

Ukazane makrostruktury (rys. 4) złączy spawanych wykonane na przekrojach poprzecznych odzwierciedlają przyjętą technikę spawania ręcznego metodą TIG. Tak dobrany sposób spawania zapewnił uzyskanie złączy charakteryzujących się poprawną budową. Dla obu wariantów staliwa tj. z dodatkiem metali ziem rzadkich oraz bez dodatku, oszacowano szerokość strefy wpływu ciepła (SWC), która zmieniała się w zakresie od 1,5 mm do 2,4 mm.

\section{Badania udarności}

Badania udarności przeprowadzono zgodnie z normą ISO 9016:2012 [13] na próbkach udarnościowych z karbem w kształcie litery V. Zastosowano próbki typu VWT z naciętym karbem w osi spoiny oraz próbki VHT z karbem naciętym w SWC. W obszarze spoiny dla obu rodzajów złączy 


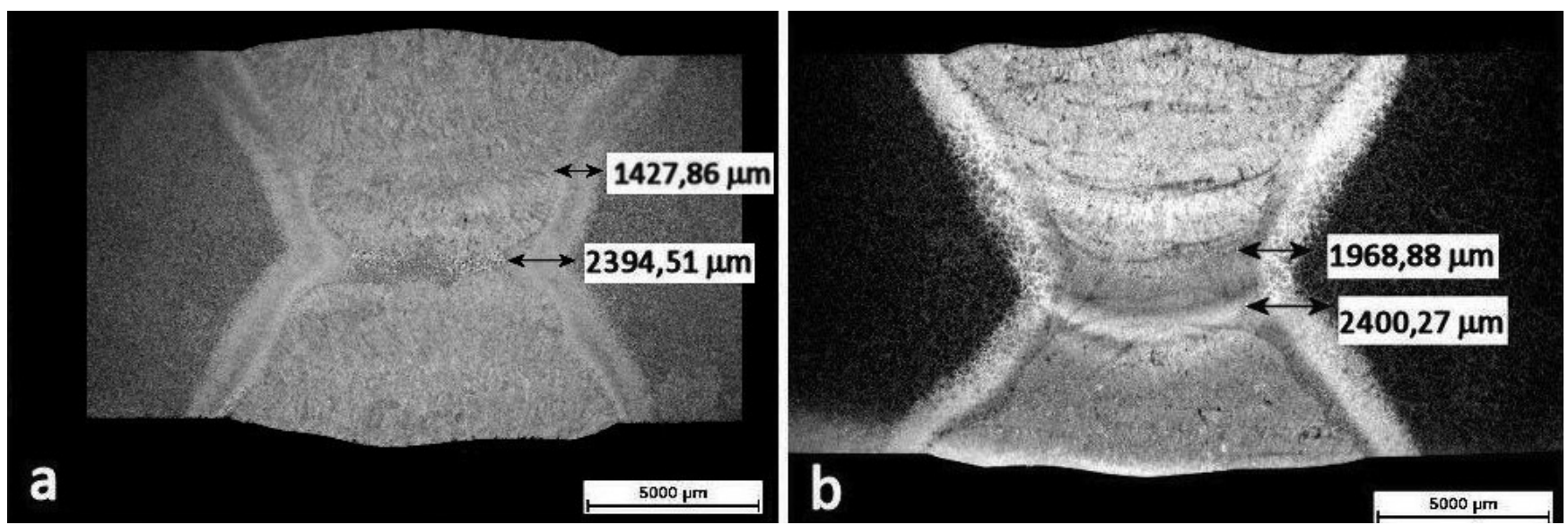

Rys. 4. Makrostruktury próbnych złączy spawanych ze staliwa G17CrMo5-5: a) staliwo niemodyfikowane, b) staliwo z dodatkiem MZR Fig. 4. Macrostructures of test welded joints made of G17CrMo5-5 cast steel: a) unmodified cast steel, b) cast steel with the addition of MZR

tj. ze staliwa niemodyfikowanego oraz z dodatkiem MZR uzyskano podobne wartości udarności. Istotny wzrost wartości udarności odnotowano w strefie wpływu ciepła dla staliwa modyfikowanego (rys. 5) [6].

\section{Morfologia przełomów udarnościowych}

Po przeprowadzeniu prób udarnościowych przełomy poddano obserwacjom mikroskopowym. Przełomy charakteryzowały się pasmem pękania ciągliwego pod dnem karbu oraz obszarem pękania kruchego w środkowym obszarze złomu. W obu przypadkach obszar pękania ciągliwego ma podobny charakter. W środkowej części przełomów obserwuje się kruchy charakter pękania z widocznymi pasmami pękania

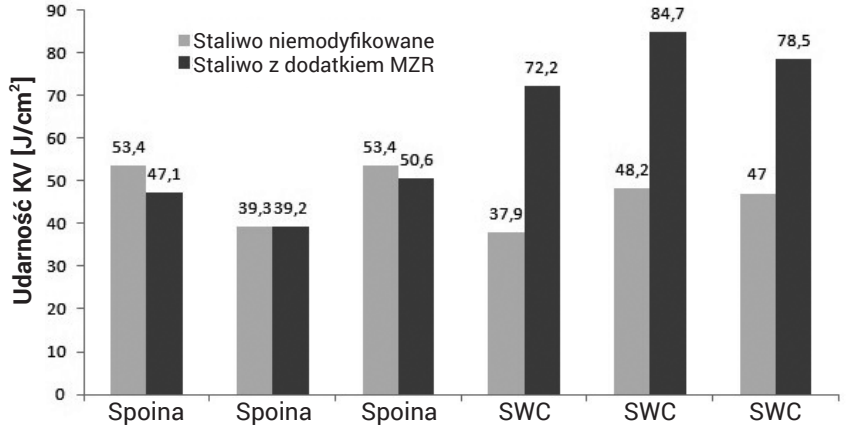

Rys. 5. Udarność KV złączy próbnych

Fig. 5. KV Impact resistance of test welded joints
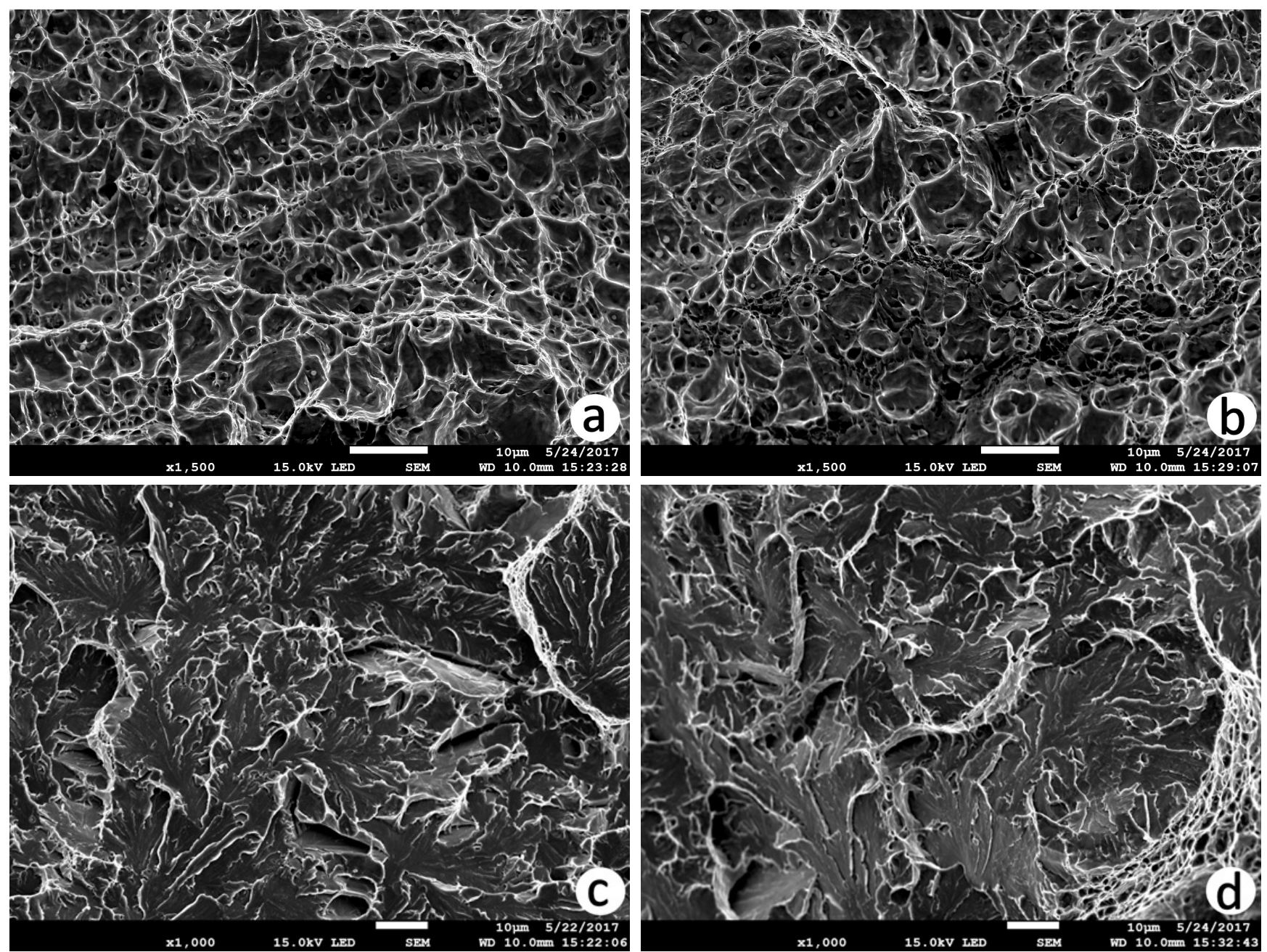

Rys. 6. Morfologia przełomów z próbek udarnościowych ze spoin: a), c) staliwo niemodyfikowane; b), d) staliwo z dodatkiem MZR

Fig. 6. Morphology of fractures from impact samples from the welds: a), c) unmodified cast steel; b), d) cast steel with the addition of MZR 
ciągliwego (rys. 6). W obszarze przełomu udarnościowego w obu przypadkach obserwuje się występowanie wtrąceń siarczkowych (rys. 7a). Dodatkowo w przypadku staliwa modyfikowanego obserwuje się sporadyczne występowanie wtrąceń zawierających w swym składzie MZR (rys. 7b) [6].

Na przełomach udarnościowych z SWC zaobserwowano występowanie siarczków żelazawo-manganawych w formie skupisk (rys. 7a, 8a). W przypadku staliwa modyfikowanego obserwuje się jedynie wydzielenia tlenosiarczków metali ziem rzadkich $w$ formie drobnych sferycznych wtrąceń (rys. 8b). W przypadku staliwa modyfikowanego zaobserwowano zwiększony udział pękania ciągliwego.
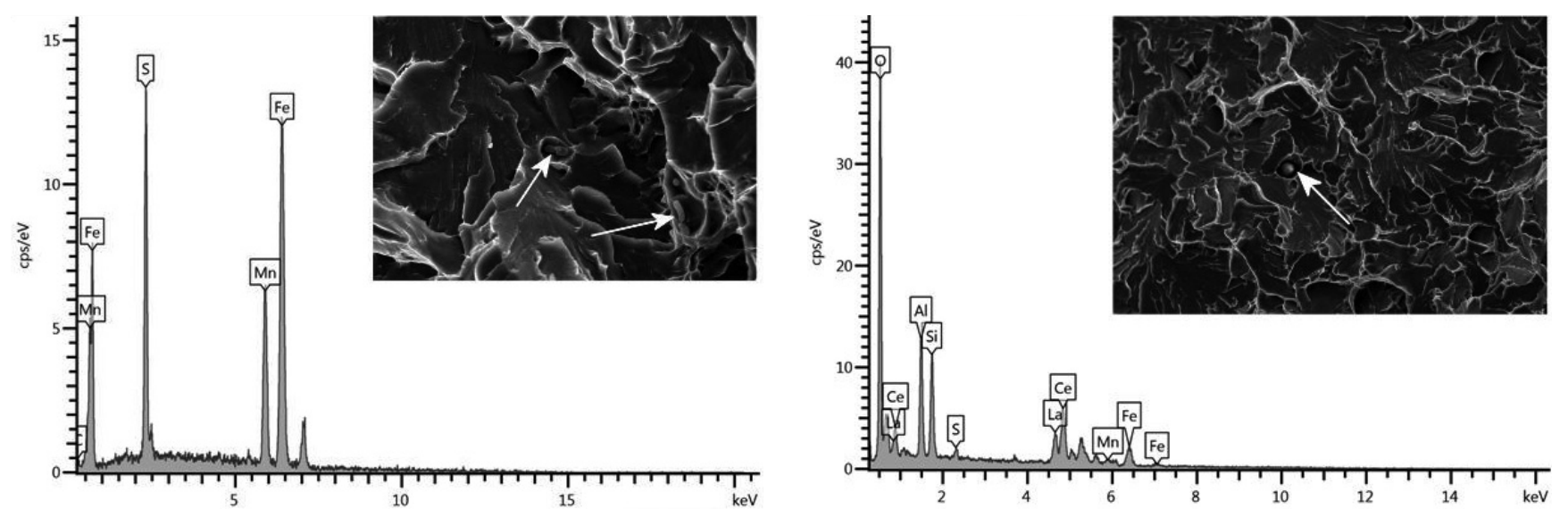

Rys. 7. Widma promieniowania rentgenowskiego: a) staliwo niemodyfikowane, b) staliwo z dodatkiem MZR Fig. 7. X-ray spectra: a) unmodified cast steel, b) cast steel with the addition of MZR
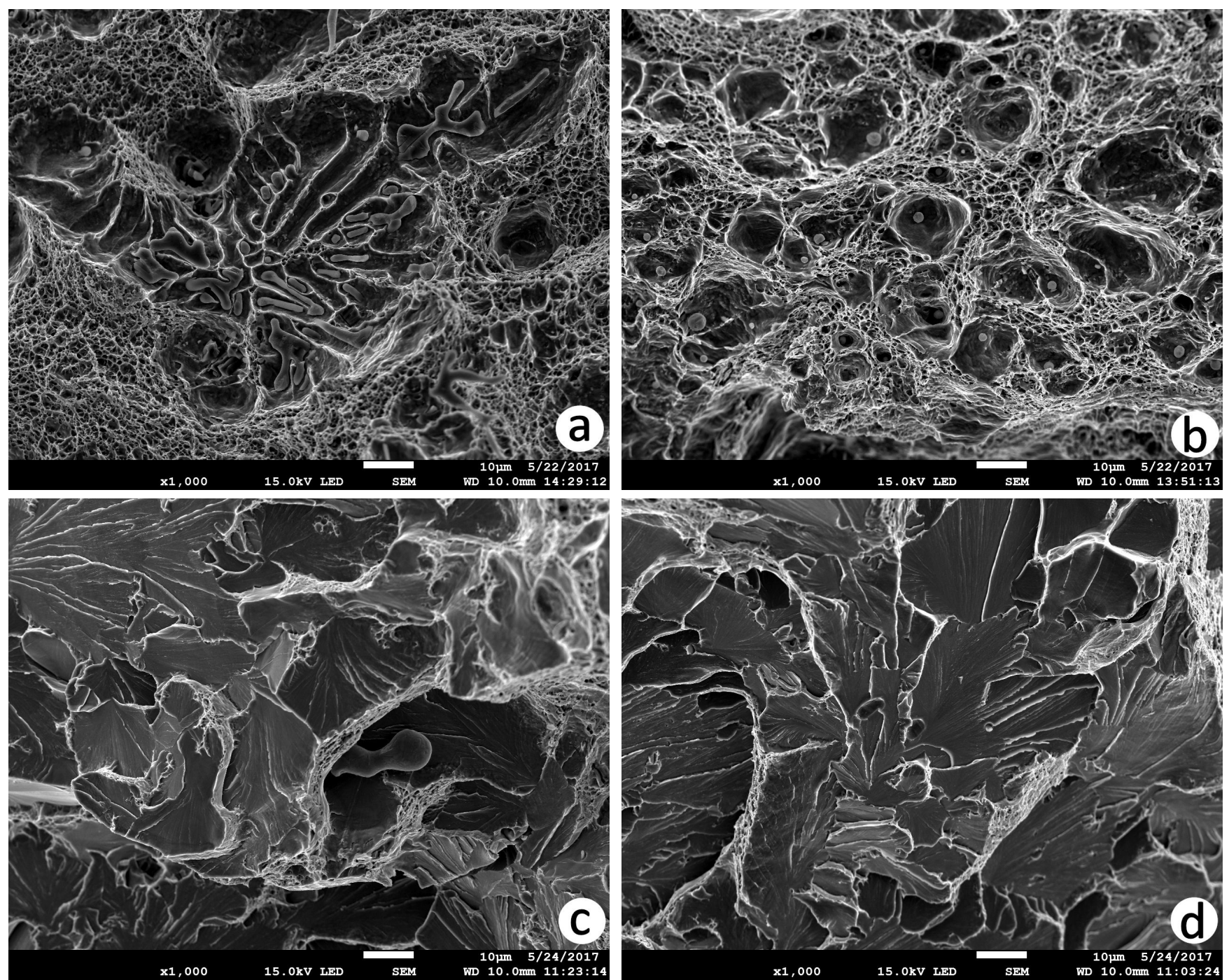

Rys. 8. Morfologia przełomów z próbek udarnościowych z SWC: a), c) staliwo niemodyfikowane; b), d) staliwo z dodatkiem MZR

Fig. 8. Morphology of fractures from impact samples with SWC: a), c) unmodified cast steel; b), d) cast steel with the addition of MZR 

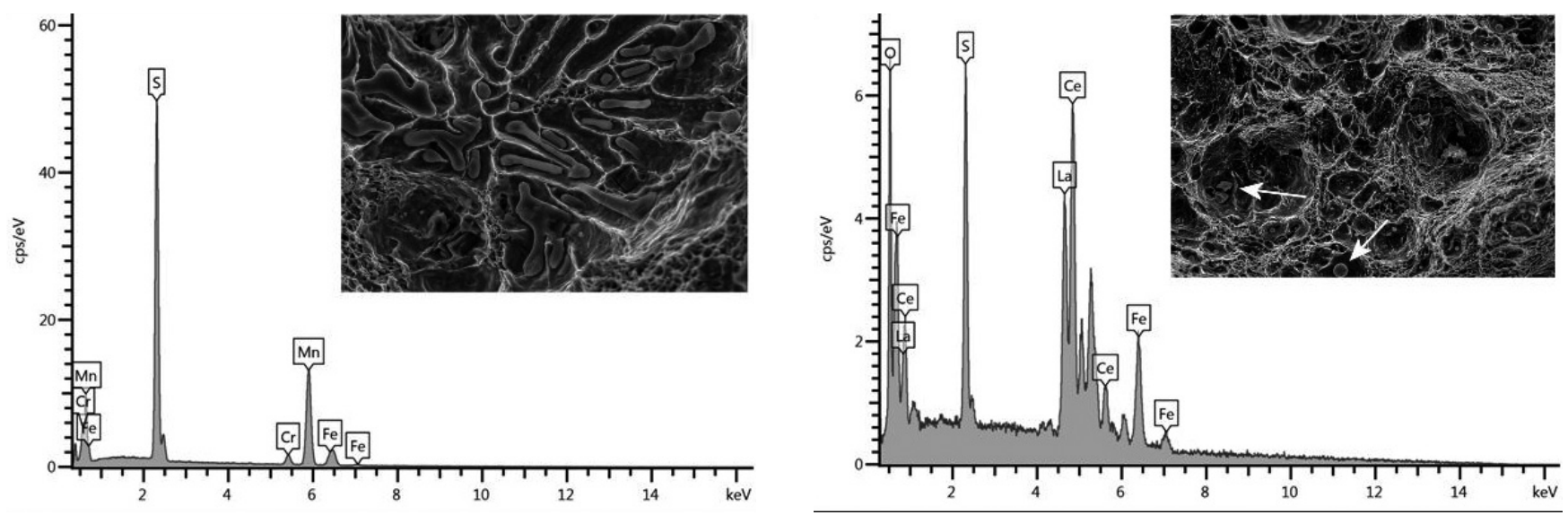

Rys. 9. Widma promieniowania rentgenowskiego: a) staliwo niemodyfikowane, b) staliwo z dodatkiem MZR

Fig. 9. X-ray spectra: a) unmodified cast steel, b) cast steel with the addition of MZR

\section{Podsumowanie}

Badania udarności dla wykonanych złączy próbnych wykazały zbliżone wartości w obszarze spoin dla analizowanych staliw. Potwierdza to analiza fraktograficzna przełomów, która wykazała podobną morfologię dla obu rodzajów staliwa tj. niemodyfikowanego oraz z dodatkiem metali ziem rzadkich. Część wtrąceń zawierających MZR pozostała niezmieniona, co wynika z ich wysokich wartości temperatur topnienia, która dla tlenosiarczków ceru i lantanu wynosi powyżej 2000 ํㅡ [14]. W przypadku staliwa niemodyfikowanego w obszarze pękania ciągliwego pod dnem karbu doszło do wydzielenia się skupisk siarczkowych, co jest efektem oddziaływania cyklu cieplnego spawania. Morfologia w środkowej części przełomu SWC w obu przypadkach ma charakter łupliwy z pasmami pękania ciągliwego, przy czym udział tego drugiego jest większy w staliwie z MZR.

Modyfikacja staliwa mieszanką cerową w postaci mischmetalu spowodowała wzrost udarności SWC złączy spawanych. Wynika to ze zmian morfologii wtrąceń niemetalicznych powstałych w procesie modyfikacji, które korzystnie oddziaływają na proces pękania złączy.

\section{Literatura}

[1] Kocańda S.: Fatigues destroying of metals, WNT, Warszawa, 1978.

[2] Kalandyk B., Zapała R., Sobula S., Górny M., Boroń Ł.: Characteristics of low nickel ferritic-austenitic corrosion resistant cast steel, Metalurgija, 53, 2014, 4, pp. 613-616.

[3] Ślęzak T., Śnieżek L., Torzewski J.: Ocena zmęczeniowego pękania stali S960QL w warunkach występowania odkształceń plastycznych, XV Krajowa Konferencja Mechaniki Pękania, Kielce, Polska, 2015.

[4] Orłowicz A.W., Mróz M., Tupaj M., Trytek A.: Ocena przełomów po badaniach zmęczeniowych stopu C355, Archives of Foundry, 5, 2005, 15, s. 298-303.

[5] Chakraborti P.C., Kundu A., Dutta B.K.: Weilbull analysis of low temperaturę fracture stress data of 20MnMoNi55 and SA333 (Grade 6) steels, Materials Science \& Engineering A, 594, 2014, pp. 89-97.

[6] Skrzypczyk A., Kasińska J., Furmańczyk P.: Analiza morfologii przełomów udarnościowych złączy spawanych ze staliwa G17CrMo5-5, Nowoczesne zastosowania technologii spawalniczych, Sympozjum Katedr i Zakładów Spawalnictwa, Istebna, 13-14 czerwca 2017 r. Praca zbiorowa. Pod red. Jacka Górki, Komisja Odlewnictwa PAN, Oddział Katowice, Gliwice, 2017, s. 291-298.

[7] Gajewski M., Kasińska J.: Rare earth metals influence on mechanical properties and crack resistance of GP240GH and G17CrMo5-5 cast steels, Archives of Foundry Engineering, vol. 9, no. 4, 2009, pp. 37-44.
[8] ASTM E 1737-96 Standard Test Method for J-Integral Characterization for Fracture Toughness American Society for Testing and Materials (ASTM), Pensylwania.

[9] Dzioba I., Kasińska J., Pała R.: The Influence Of The Rare Earth Metals Modification On The Fracture Toughness Of G17CrMo5-5 Cast Steel At Low Temperatures, Archives of Metallurgy and Materials, 60, 2015, 2A, pp. 773-777.

[10] Skrzypczyk A., Kasińska J.: Spawanie staliwa Cr-Mo z dodatkiem pierwiastków ziem rzadkich metodą TIG, Przegląd Spawalnictwa, vol. 89 (6), 2017, s. 10-14.

[11] PN-EN ISO 21952-A Materiały dodatkowe do spawania - Druty elektrodowe.

[12] PN-EN ISO 14175:2009P Materiały dodatkowe do spawania - Gazy i mieszaniny gazów do spawania i procesów pokrewnych.

[13] ISO 9016:2012 Destructive tests on welds in metallic materials - Impact tests - Test specimen location, notch orientation and examination.

[14] Waudby P.E.: Rare earth additions to steel, Inter. Metals Rev.,T23, 1978. 